\title{
Observational study of HSG with laparoscopic correlation in infertility patients
}

\author{
Avinash Dubbewar ${ }^{1}$, Saumen Kanti Nath ${ }^{2 *}$ \\ ${ }^{1}$ Department of Obstetrics and Gynecology, ${ }^{2}$ Department of Radiodiagnosis, Military Hospital Devlali, Nasik, \\ Maharashtra, India
}

Received: 08 March 2018

Accepted: 05 April 2018

*Correspondence:

Dr. Saumen Kanti Nath,

E-mail: saumennath73@gmail.com

Copyright: $\odot$ the author(s), publisher and licensee Medip Academy. This is an open-access article distributed under the terms of the Creative Commons Attribution Non-Commercial License, which permits unrestricted non-commercial use, distribution, and reproduction in any medium, provided the original work is properly cited.

\section{ABSTRACT}

Background: Uterine abnormalities contribute to $10 \%$ of infertility cases and $50 \%$ of women with recurrent early pregnancy loss whereas fallopian tube abnormalities contribute to $20 \%$ of such cases.

Methods: Total 61 patients of infertility and subfertility undergoing evaluation and treatment at our centre were selected for HSG. Total 25 patients from this group have undergone diagnostic laparoscopy, their findings were correlated with HSG findings retrospectively.

Results: All the patients in the study group were either primary or secondary infertility patients. Of the 61 patients of infertility, 49 were in primary infertility group and 12 were in secondary infertility group. The age of patients was between 23 and 35 years. The average duration of primary infertility was 5 years and secondary infertility was 3.5years. Total 61 patients underwent HSG, 42(68.8\%) patients had normal findings and 19(31.14\%) patients had abnormal findings. In abnormal findings $4(6.55 \%)$ were Mullerian abnormalities and $15(24.59 \%)$ were either unilateral or bilateral tubal block. Total 25 patients underwent diagnostic laparoscopy out of 61 patients. The sensitivity of HSG was $90 \%$ and specificity was $60 \%$ with positive predictive value of $60 \%$ and negative predictive value of $90 \%$ as compared to diagnostic laparoscopy. Tubal block was defined as any form of tubal occlusion detected at HSG and finally confirmed on laparoscopy. In our laparoscopy findings, peri-adnexal adhesions were found in $5(20 \%)$ of the blocked tubes on laparoscopy. Endometriosis was detected in $1(4 \%)$ of the blocked tubes and suspected intra-tubal block in $2(8 \%)$.Pelvic inflammatory disease was found to contribute in $3(12 \%)$.

Conclusions: HSG demonstrates high sensitivity in our study. So, it should be used as the initial investigation for identifying uterine abnormality and tubal patency. As the specificity is less, we suggest that laparoscopy is necessary to recognize those cases of tubal block, which were unrecognized or wrongly recognized on HSG. In addition, the patients who were found to have tubal block on HSG, laparoscopy helps in finding the cause of infertility like existence of peritubal adhesions and endometriosis that can guide appropriate therapy.

Keywords: Bicornuate uterus, Hysterosalpingography, Laparoscopy, Tubal occlusion unicornuate uterus

\section{INTRODUCTION}

Infertility is defined as the inability to conceive after one year of unprotected intercourse of reasonable frequency. It is mainly of two types, Primary and Secondary infertility. Most of the clinicians will start evaluation of couple after one year. Approximately 25 to 30 percent of all infertile women are diagnosed with tubal disease in developing countries. ${ }^{1,2}$ Genital tuberculosis may account for $3-5$ percent of infertility cases in developing countries including India Congenital or acquired uterine abnormalities also contribute to infertility or subfertility in females. ${ }^{3,4}$ Congenital abnormalities are uterine septum, unicornuate uterus, bicornuate uterus. Acquired 
anomalies are like intrauterine leiomyomas, polyps or synechiae, which all can be causes of subfertility too. ${ }^{5-9}$

During investigations HSG is first line approach to assess the patency of fallopian tubes and uterine anomalies However, despite tubal patency being demonstrated by HSG, laparoscopy has shown better detection of tubal patency with additional information of peritubal adhesions and endometriosis. ${ }^{10,11}$ HSG is less invasive test compared to diagnostic laparoscopy and safe, rapid and cost effective also.

Uterine abnormalities contribute to $10 \%$ of infertility cases and $50 \%$ of women with recurrent early pregnancy loss whereas fallopian tube abnormalities contribute to $20 \%$ of such cases. ${ }^{12,13}$

\section{METHODS}

61 patients of primary and secondary infertility after complete evaluation underwent HSG. 25 patients from these patients underwent Diagnostic Laparoscopy in a secondary care hospital from Dec 2016 to Jan 2018.

\section{Contrast Media}

Water soluble dyes have been found to provide better detail of uterine cavity and mucosal folds of the ampullary portion of the tube and are more quickly eliminated..$^{14}$

In the present study, we have used Urografin $76 \%$ and Ultrascan $60 \%$. 1 Rad or $10 \mathrm{mGy}$ for upto $10 \mathrm{mins}$ (100Gy total) has been suggested as the threshold below which the added incidence of teratogenicity is exceedingly low. The radiation dose to the ovaries during HSG varies from $0.4 \mathrm{t}-5.5 \mathrm{~Gy} .{ }^{15}$

HSG was performed between day 5 to day 10 of cycle to avoid possible pregnancy. Patients were made to lie down in dorsal lithotomy position, Cervix and vagina were cleaned with antiseptic solution and then cervix was held with the help of Sims speculum and valsellum.

Prefilled with water soluble dye, Lych Wilkinson canula of appropriate size was introduced in cervical canal. Serial spot radiographs were taken during uterine filling phase after injecting 3-4 cc of dye followed by another 3$4 \mathrm{cc}$ for visualization of tubal image and spillage as shown in Figure 1.

Patients were given Diclofenac suppository 100mg per rectal $30 \mathrm{~min}$ before the procedure for analgesia. No antibiotics were given except in two patients.

Diagnostic laparoscopy was done in patients who did not conceive with 2 cycles of Intra uterine insemination after HSG or had abnormal findings on HSG. Procedure was done under general anesthesia after preoperative evaluation. Patients were in lithotomy position. Parts preparation was done, and subsequently uterine manipulator was introduced through cervix for visualization and introduction of dye. Primary ports were introduced through umbilical incision and secondary port in right side of abdomen. Anatomical inspection and evaluation of abdomen was done and finding noted. Finally, methylene blue was introduced through manipulator and its spillage in abdominal cavity through bilateral fallopian tubes were noted.

\section{Complications of HSG}

No major complications were encountered In the present study; however, patients who complained of post procedural pain were given oral NSAIDs for 3 days.

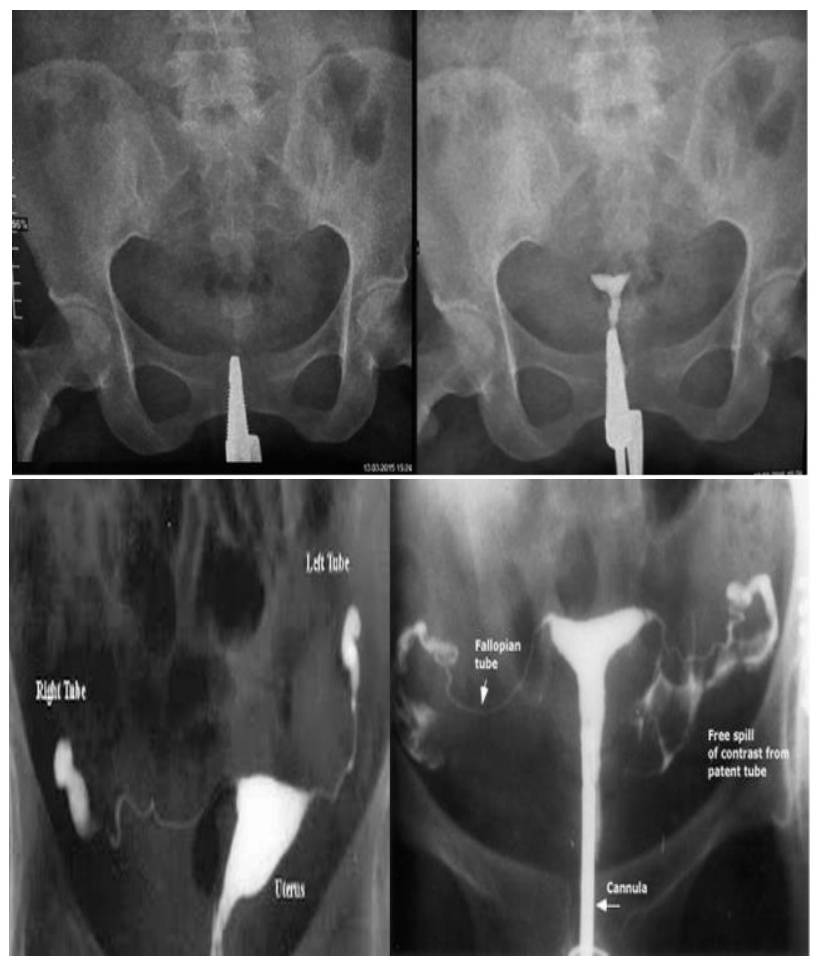

Figure 1: $4 \mathrm{cc}$ for visualization of tubal image and spillage.

\section{RESULTS}

All the patients in the study group were either primary or secondary infertility patients. Of the 61 patients of infertility, 49 were in primary infertility group and 12 were in secondary infertility group. The age of patients was between 23 and 35 years. The average duration of primary infertility was 5 years and secondary infertility was 3.5 years.

Total 61 patients underwent HSG, $42(68.8 \%)$ patients had normal findings and $19(31.14 \%)$ patients had abnormal findings. In abnormal findings 4 (6.55\%) were mullerian abnormalities and 15 (24.59\%) were either unilateral or bilateral tubal block. Total 25 patients 
underwent diagnostic laparoscopy out of 61 patients as shown in Figure 2 and 3.

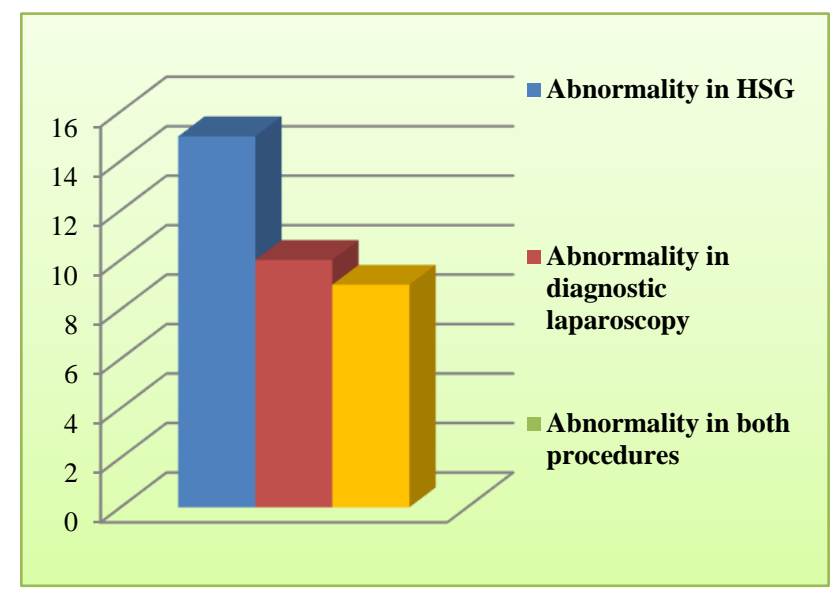

Figure 2: Comparison of abnormal findings in HSG and Diagnostic laparoscopy.

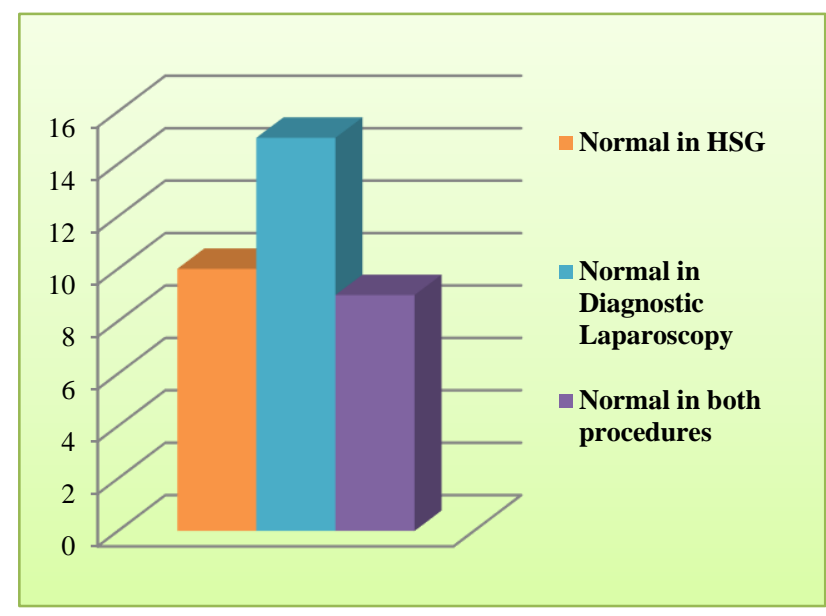

Figure 2: Comparison of normal findings in HSG and Diagnostic laparoscopy

The sensitivity of HSG was $90 \%$ and specificity was 60 $\%$ with positive predictive value of $60 \%$ and negative predictive value of $90 \%$ as compared to diagnostic laparoscopy as shown in Table 1.

Table 1: Relative risk of abnormal Doppler indices with adverse perinatal outcome.

\begin{tabular}{|llll|} 
& $\begin{array}{l}\text { Diagnostic } \\
\text { lap positive }\end{array}$ & $\begin{array}{l}\text { Diagnostic } \\
\text { lap negative }\end{array}$ & Total \\
\hline HSG positive & 9 & 6 & 15 \\
\hline HSG negative & 1 & 9 & 10 \\
\hline Total & 10 & 15 & \\
\hline
\end{tabular}

Tubal block was defined as any form of tubal occlusion detected at HSG and finally confirmed on laparoscopy.

In our laparoscopy findings, periadnexal adhesions were found in $5(20 \%)$ of the blocked tubes on laparoscopy.
Endometriosis was detected in $1(4 \%)$ of the blocked tubes and suspected intratubal block in $2(8 \%)$.Pelvic inflammatory disease was found to contribute in $3(12 \%)$.



Figure 4: Sensitivity, specificity, positive and negative predictive values.

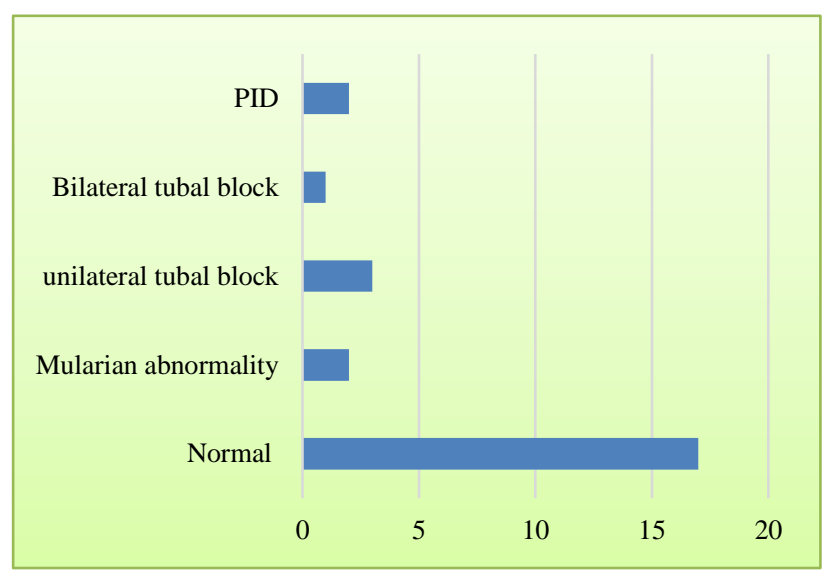

Figure 5: Findings in diagnostic laparoscopy.

\section{DISCUSSION}

Infertility is defined as one year of unprotected intercourse without conception. Incidence of infertility has remained relatively constant over last three decades. Infertility varies across regions of the world and is estimated to affect 8 to 12 per cent of couples worldwide one of the major causes for infertility in India is tubal and peritoneal factors, which accounts for $30-40 \% .^{16-19}$

Authors try to look mainly for these factors by doing HSG and Diagnostic laparoscopy. HSG shows the shape and size of uterine cavity and define tubal status; it is an excellent predictor of tubal patency but not for peritubal and pelvic adhesions.

Laparoscopy is more invasive test than HSG but has the advantage of detecting peritoneal and peritubal factors as compared to HSG, which makes it gold standard for detection of peritoneal and tubal factors especially when HSG results are abnormal. 
In the present study, a total of 61 patients were selected as per inclusion criteria. Out of these 61 cases, primary and secondary infertility were 49 and 12 respectively. 42 (68.85\%) HSG were normal and 19 (31.14\%) HSG were having abnormal findings. Out of 19 abnormal cases, Mullerian anomalies constituted $4(6.55 \%)$ with 2 cases of arcuate uterus and single case of bicornuate uterus and unicornuate uterus each. The other type of abnormalities investigated were $15(24.59 \%)$ cases of tubal block, unilateral and bilateral as shown in Figure 6.

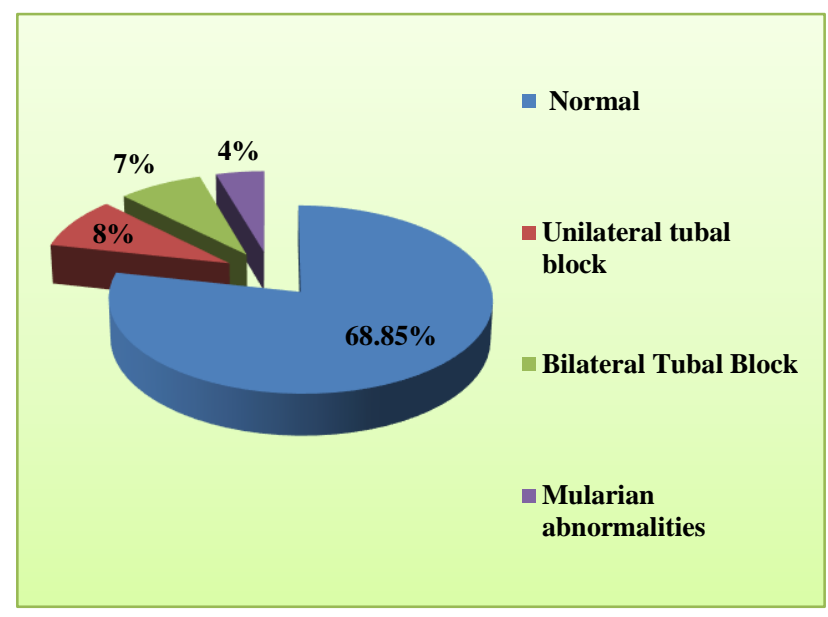

Figure 6: Findings in diagnostic laparoscopy.

Follow up of 61 patients of HSG, who underwent diagnostic laparoscopy were 25. Percentage of normal findings were $17(68 \%)$ and abnormal findings were $8(32 \%)$. 18 laparoscopies corroborated exactly same with the findings of HSG whereas 7 were non-corroborative. All 7 patients were having either unilateral or bilateral tubal block which was not found during diagnostic laparoscopy. This can be explained by tubal contractions (cornual spasm) or unilateral block due to dye following path of least resistance even if contralateral tube is patent. This finding also confirms that laparoscopy is superior and definitive for prediction of tubal blocks compared to HSG alone. Remaining 8 cases of tubal block on HSG were confirmed by laparoscopy, there were 4 cases of peritubal adhesions with features suggestive of PID, 1 case of endometriosis and 3 cases of B/L tubal block with normal laparoscopic findings (intra tubal blocks) as shown in Figure 5. Laparoscopy has given exact reasons for tubal blockage making it superior to HSG for assessing extra-tubal pathology. ${ }^{20,21}$

In the present study, we have taken into consideration the diagnostic laparoscopy as the reference standard in detecting tubal blockage. We compared HSG findings of tubal patency with laparoscopic chromotubation findings and found a sensitivity of $90 \%$ (95\% CI :76.43-96.86) and specificity was 60\%(95\%CI 59.24-89.39) which were comparable with study by Gokhan Goynumer et al which showed sensitivity and specificity of $80 \%$ and $75 \%$ respectively when tubal block was defined as either unilateral or bilateral. ${ }^{22}$ Another study in the year 2016 by Syeed Masuma Rizvi et al also shows similar results. ${ }^{23}$

\section{CONCLUSION}

HSG demonstrates high sensitivity in the present study. So, it should be used as the initial investigation for identifying uterine abnormality and tubal patency. As the specificity is less, we suggest that laparoscopy is necessary to recognize those cases of tubal block, which were unrecognized or wrongly recognized on HSG. In addition, the patients who were found to have tubal block on HSG, laparoscopy helps in finding the cause of infertility like existence of peritubal adhesions and endometriosis that can guide appropriate therapy.

\section{ACKNOWLEDGMENTS}

We convey our sincere thanks to the radiographers during procedure and the lady attendants without whose support the study should not have been complete.

Funding: No funding sources

Conflict of interest: None declared

Ethical approval: The study was approved by the Institutional Ethics Committee

\section{REFERENCES}

1. Serafini P, Batzofin J. Diagnosis of female infertility. A comprehensive approach. J Reprod Med. 1989;34:29-40.

2. World Health Organization: Women and sexually transmitted infections. 2007. Available at: http://www.who.int/mediacentre/factsheets/fs110/en. /Accessed August 21, 2010

3. Aliyu MH, Aliyu SH, Salihu HM. Female genital tuberculosis: a global review. Int J Fertility and Women's Medi. 2004;49:123-36.

4. Nezar M, Goda H, El-Negery M, El-Saied M, Wahab AA, Badawy AM. Genital tract tuberculosis among infertile women: an old problem revisited. Archives of Gynecol and Obstet. 2009;280:787-91.

5. American Society for Reproductive Medicine: Myomas and reproductive unction. Fertil Steril 90 (Suppl 3):S125, 2008b

6. Makker A, Goel MM: Uterine leiomyomas: e ects on architectural, cellular, and molecular determinants of endometrial receptivity. Reprod Sci. 2013; 20(6):631.

7. Metwally M, Cheong YC, Horne AW: Surgical removal of fibroids does not improve fertility outcomes. Cochrane Database Syst Rev. 2012;11:CD003857.

8. Pritts EA. Fibroids and infertility: a systematic review of the evidence. Obstet and Gynecol survey. 2001;56:483-91.

9. Samejima T, Koga K, Nakae H, Wada-Hiraike O, Fujimoto A, Fujii T, Osuga Y. Identifying patients 
who can improve fertility with myomectomy. Eur J Obstet Gynecol Reprod Biol 185C:28,2014

10. Balasch J. Investigation of infertile couple: investigation of infertile couple in the era of assisted reproductive technology. A time for reappraisal Hum Reprod. 2000;15:2251-57.

11. Simon A, Laufer N. Unexplained infertility: a reappraisal. Ass Reprod Rev. 1993;3:26-36.

12. Brown SE, Coddington CC, Schnorr J, Toner JP, Gibbons W,Oehninger S. Evaluation of outpatient hysteroscopy, saline infusion hysterosonography in infertile women: a prospective, randomised study. Fertil Steril. 2000;74:1029-34.

13. Brunham RC, Maclean IW,Binnis B,Peeling RW. Chlamydia trachomatis:its role in tubal infertility. J Infect Dis. 1985.152:1275-82

14. Lindequist S, Justesen P, Larsen C, Rasmussen F. Diagnostic quality and complications of HSG: oilversus water soluble contrast media-a randomised prospective study. Radiol. 1991.179:69-74.

15. Karande VC, Pratt DE, Balin MS, Levrant SG, Morris RS, Gleicher N. What is the radiation exposure to patients during a gynaecological procedure? Fertile steril. 1997;67(2):401-3.

16. Sciarra J. Infertility: an international health problem. Int J Gynaecol Obstet. 1994;46:155-63.

17. Population Council. Infertility. Looking back, looking forward: a profile of sexual and reproductive health in India. New Delhi, Population Council; 2004;67-72.

18. Jonathan S Berek. Bereks and Novaks Gynaecology$15^{\text {th }}$ ed. $32 ; 1157$.

19. Marc A. Fritz Clinical Gynecologic Endocrinology and Infertility- ${ }^{\text {th }}$ ed: $27 ; 1156$.

20. Sharma R, Sharma V. The infertile woman: a study of 120 cases. J Indian Med Assoc. 1991;89:31-2.

21. Swart P, Mol BW, van der Veen F, van Beurden ,Redekop WK, Bossuyt PM. The accuracy of hysterosalpingography in diagnosis of tubal pathology: a metaanalysis. Fertil Steril. 1995; 64:486-91.

22. Gokhan G, Gamze Y, Oznur G, Isin K, Lale W, Birolt D. Hysterosalpingography, Laparoscopy or both in the diagnosis of tubal disease in infertility. World J Laparos Surg. 2008;1:23-26.

23. Rizvi SM, Ajaz S, Gulshan, Nikita, Anjum S, Inara. Comparison of Hysterosalpingography and laparoscopy in diagnosis of tubal occlusion. Ann Int Med Den Res. 2016;2:165-8.

Cite this article as: Dubbewar A, Nath SK. Fetal Observational study of HSG with laparoscopic correlation in infertility patients. Int $\mathbf{J}$ Reprod Contracept Obstet Gynecol 2018;7:1903-7. 